\title{
Quality in Health Care: Whose Responsibility Is It?*
}

\author{
Avedis Donabedian, M.D. ${ }^{\dagger}$
}

Nathan Sinai Distinguished Professor Emeritus of Public Health, School of Public Health, The University of Michigan, Ann Arbor, Michigan

My subject is billed as "Quality-Whose Responsibility Is It?" This is a stunningly broad topic, especially nowadays, when the concept of "total quality" is so easily bandied about. So, I could cut down my subject to a somewhat smaller size by changing it to: "Quality in Health Care-Whose Responsibility Is It?" But even when I circumscribe it this way, the domain of inquiry is so large that there can be only one answer: everybody's. This is perfectly true; but I don't think I will earn my honorarium or you your continuing education points, if I stop there. We need to delve deeper.

In order to proceed in a reasonably systematic way, I would like us to agree on a number of things: (a) the meaning of quality in health care; (b) the relevant actors or players; and (c) the configuration of the stage or playing field. I believe that after we have done this, we shall be able to explore in a more orderly way who is responsible, for what, in what way, and why. But please remember that the subject is so vast, and our time so limited, that I shall have to paint in the broadest of strokes, perhaps omitting or distorting many details.

\section{THE MEANING OF QUALITY}

I shall conceive of quality in health care as the product of two elements, as shown in Fig. 1: (a) the fundamental attributes of the science and technology of health care; and (b) the ways in which the science and technology of health care are applied in practice.

\footnotetext{
* This paper was commissioned for the CME Seminar held under the auspices of the American Board of Quality Assurance and Utilization Review Physicians, Clearwater, Florida, February 1216,1992 , but the author is solely responsible for the opinions expressed in it.

$\uparrow$ To whom requests for reprints should be addressed at 1739 Ivywood, Ann Arbor, MI 48103.
}

The first of these describes the tools, and the second describes the ways in which the tools are used.

The quality of health care that results from the interaction of these two elements has seven major attributes, also shown in Fig. 1. These are defined briefly as follows.

Efficacy: The ability of the science and technology of health care to bring about improvements in health, when used under the most favorable circumstances.

Effectiveness: The degree to which improvements in health now attainable are, in fact, attained.

Efficiency: The ability to lower the cost of care without diminishing attainable improvements in health.

Optimality: The balancing of improvements in health against the costs of attaining such improvements.

Acceptability: Conformity to the wishes, desires, and expectations of patients and responsible members of their families.

Legitimacy: Conformity to social preferences as expressed in ethical principles, values, norms, mores, laws, and regulations.

Equity: Conformity to a principle that determines what is just and fair in the distribution of health care and its benefits among the members of a population.

\section{THE HEALTH CARE PLAYING FIELD}

The major players in the game of health care are identified diagrammatically in Fig. 2. These are very rough classifications that should be regarded as designating separable roles, rather than mutually exclusive entities. This picture is highly influenced by my own perspectives and prejudices. Someone else, with a different background, or a different set of responsibilities, would draw the picture differently. 


\section{PATIENTS, PRACTITIONERS, AND THEIR INTERACTION}

I place the interaction of patients and practitioners at the center of the health care universe because I believe that it is there that the processes and decisions most critical to quality take place. Here is the atomic furnace where quality is generated. I say "generated" because one must not conceive of care as tendered by practitioners and accepted by patients. Rather, it should be the product of the free, equal, and fully informed participation of the two.

It is the responsibility of practitioners to arrive at an accurate assessment of the patient's condition and circumstances; to know the range of interventions that the science and technology of health care currently

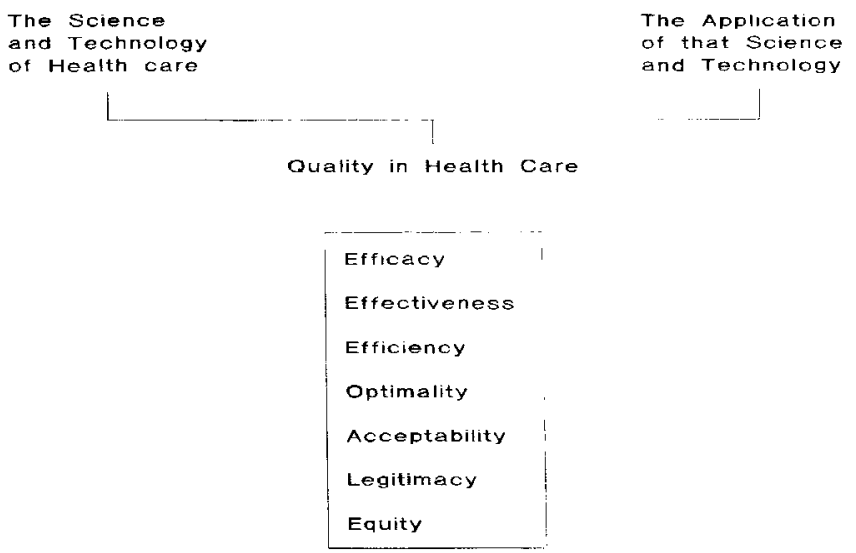

Fig. 1. Components of quality in health care.

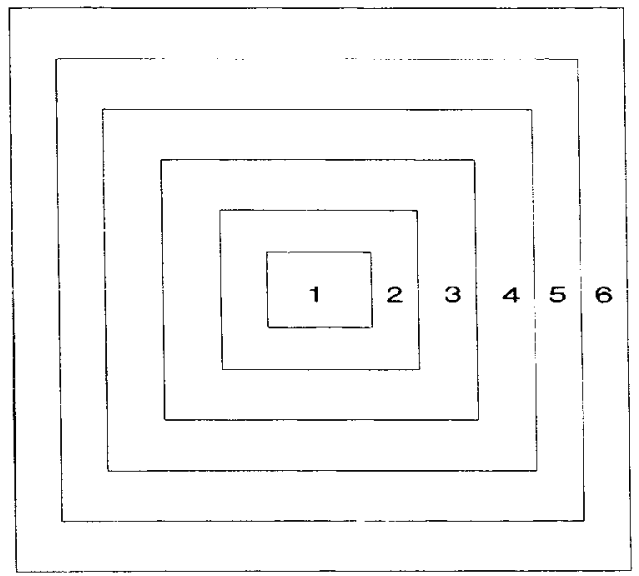

Fig. 2. The health care playing field. 1, patients, practitioners, and their interaction; 2 , institutional providers; 3 , organizations of consumers, professionals, and institutional providers; 4 , insurers and collective purchasers; 5 , researchers, developers, educators, and their organizations; 6 , policy-makers and regulators. have to offer; to convey that information to the patient; to arrive at the most appropriate intervention in consultation with the patient and with regard to the patient's circumstances and preferences; and to be able to execute the chosen intervention in the most skillful way possible.

The patient's responsibility is to seek care from the appropriate source at the appropriate time; to provide the information necessary for a correct assessment of the patient's condition and circumstances; to participate fully in deciding on the most appropriate plan of management; and to participate fully and skillfully in the implementation of that management plan.

All these interactions should conform to the conventions of civilized exchange between equals in our society, with special care taken to prevent the vulnerabilities peculiar to the patient role from being manipulated or exploited in any way. How does this description of the idealized patient-practitioner relation pertain to the attributes of quality I have already mentioned?

Obviously, I have tried to include in my description of the patient-practitioner interaction features that make it pleasant and rewarding for the patient and, I hope, for the practitioner as well. Acceptability, therefore, is an important goal. So is effectiveness, since both practitioners and patients aim to attain the greatest improvement in health now possible, but not on any absolute scale. Rather, the improvement aimed for is calibrated and assessed in a way that takes into account those aspects of well-being and function that are most valuable to the patient, including improvements in both the quantity and quality of life and the balance of the two.

Should cost be a factor in these deliberations? Obviously, it is incumbent on both the patient and practitioner to choose those forms of management that reduce cost without reducing the expectation of improvements in health. The scarcity of our resources renders anything else totally irresponsible. It follows that practitioners are responsible for being well informed about the costs of alternative strategies of care, in addition to their effects, so that they can advise their patients accordingly.

In the pursuit of efficiency, the only question is that of the incidence of costs, specifically, costs to whom? In my opinion it is cost to the patient that should enter the determination of what is most efficient. Unfortunately, because of the incomplete nature of health care coverage, what is least costly to patients may not be least costly to the financing program. This discrepancy is the root of a conflict between underwriters and the patient-practitioner alliance.

The conflict is more severe and intractable when 
optimality becomes a goal in care. It seems to me that the balancing of costs against improvements in health is a perfectly legitimate, even necessary, consideration in the patient-practitioner exchange, so long as cost to the patient and benefit to the patient are the considerations being balanced and the patient can make an informed choice. Conflict arises when one includes in the process of balancing the costs incurred by a third party, usually an underwriter, and benefits to persons other than the patient, e.g., other persons in the community.

Those who design and implement financing programs are responsible for setting them up in ways that reduce the risk of damaging the patient-practitioner bond, but I recognize that resources are scarce, and some scheme for allocation is necessary. Still, I do not believe that the practitioner-patient interaction is the place where rationing decisions are to be made. They should be made wherever health care policy is formulated and should appear as constraints within which the patient-practitioner relation is conducted. Constantly straining against these limitations, each individual practitioner is responsible for doing what is best for each patient.

Some believe it would be an act of kindness to keep the patient ignorant of superior alternatives for care that are not available to the patient. I think otherwise. I believe practitioners should explain the nature and source of external constraints that limit care. Doing so is their contribution to enlightenment. Professional organizations are responsible for sustaining and expanding this educational effort so that consumers can act responsibly in the political choices they make. Professional organizations have some additional responsibilities in this respect: (a) to advocate a larger share of resources for the health care sector; then (b) to provide policy-makers with the most accurate current information pertinent to rationing decisions; and (c) to propose the most equitable rationing mechanisms that can be devised.

Accurate information plays a vital role in all facets of quality in health care. In fact, one could make a case for placing researchers, developers, and communicators at the very center of our playing field. Much that we recognize as quality in health care derives from their efforts.

Policy-makers are responsible for supporting, encouraging, and rewarding these efforts. But it is also the responsibility of researchers to modify some of their methods and to broaden the scope of their inquiry. Rather than attempting a critique, let me emphasize certain responsibilities:

1. Assessing and validating the large accumulation of methods of care established by convention but not yet subjected to scientific testing

2. Expanding tests of efficacy so they take into consideration aspects of the quality of life, take account of the modifying influence of patient preferences in the valuation of means and of effects, and include long-term consequences in addition to short-term effects

3. Supplementing tests of efficacy under near-ideal conditions with tests of effectiveness under the various circumstances of everyday practice

4. Supplementing tests of efficacy and effectiveness with measurements of costs, to allow for a balancing of costs and benefits

5. Resisting the premature release of innovations not yet fully tested

6. Accepting greater responsibility for communicating information about what is certifiably useful now and what has become obsolete

7. Establishing a linkage between the places where new knowledge is generated and assessed and those where the criteria and standards for monitoring the quality of health care are formulated and adopted

Whenever one mentions criteria and standards, quality assessment comes to mind, and whenever assessment is mentioned, quality assurance cannot be far behind. I hope we shall not get bogged down in a debate over the most appropriate words to use to describe the activity I am about to discuss. Rather, let us see if we can agree on what the thing itself is and who is responsible for it.

I shall assume that quality assurance has four major components, or requirements, as shown in Table 1 . I have already spoken about the science and technology of health care.

The quantity and quality of human and material resources is determined most broadly by societal values and the consequent national policy that allocates resources to the health care function; more proximately, they are determined by the institutional providers that house, as it were, the patient-practitioner interaction; and in between they are determined by

\section{Table 1}

\section{Some Requirements for Quality Assurance}

\footnotetext{
Cognitive resources:

The science and technology of health care

Human and material resources:

Professional and other personnel, facilities, equipment, supplies Information pertinent to each of the several attributes of quality A system of incentives and disincentives (controls) responsive to information about performance
} 
the willingness of consumers to pay for care, of intermediaries to underwrite it, and of the organized professions to undertake the necessary tasks of recruitment, education, training, certification, and so on. Each of these players has corresponding responsibilities.

Responsibility for obtaining, processing, and disseminating information about performance pervades the entire system. Practitioners are responsible, of course, for obtaining accurate, complete information pertinent to management. This information, entered and preserved primarily in the medical record, guides current and future care and is indispensable as a means for judging performance either by the practitioners themselves or by others.

But this "cellularized" type of information gives only a fragmented picture of performance, much perturbed by the random influences that cloud all data. It is necessary to aggregate and process the information to give each practitioner, as well as practitioners collectively, an epidemiologically valid picture of individual and group performance, controlled for the effects of known intervening factors and amenable to tests of statistical significance.

Another consequence of aggregation, adjustment, and statistical presentation is that the information, after appropriate editing, can be shared with administrators and trustees of corporate providers, insurers, organized purchasers, regulators, policy-makers, and the public at large. However, besides having a claim on information generated by practitioners, each of these other parties has an independent role in collecting, processing, interpreting, and using information pertinent to quality.

In this way, corporate providers monitor the care they are responsible for, and corporate purchasers verify that value has been received for money spent. In particular, there is a responsibility for informing the public so that consumers can make informed choices in seeking care. So far we have made little progress in this respect.

A system of incentives and disincentives lies at the very heart of quality assurance. To a considerable degree, these are innate to the values that govern the behaviors of patients, professionals, administrators, and so on. But these fundamental inclinations of the mind and spirit are reinforced or attenuated by many influences from without. In a society such as ours, market forces have embodied, and continue to embody, a whole bundle of incentives and disincentives, but these have acted rather haphazardly because they were not guided by timely, accurate, and comprehensible information about health care performance. It is a fundamental principle that incentives and disincen- tives are blind to our purposes until they are guided by the appropriate information.

Recognized deficiencies in the ability of markets to provide the appropriate incentives and disincentives, coupled with significant departures from a free market in our health care system, have increased our reliance on regulation. The smaller departures in this direction consist of artificially constructed forms of reimbursement to professional and institutional providers. While these tend to discourage certain behaviors inimical to quality, they often replace them with other behaviors, also inimical, but in different ways. They have to be supplemented, therefore, by more direct forms of control: some governmental, some legal, others professional, and still others administrative. Whatever their format or auspices, regulatory interventions are restrictive and coercive; they tend to discourage rather than enliven, to enslave rather than free.

The more vital and effective incentives, it seems to me, are those that recognize good performance and reward it in ways that are meaningful to professionals and all others involved in the health care transaction-ways that include, but are not restricted to, financial rewards. I believe that the most important reason for our inability to progress more decisively in our efforts to protect and enhance the quality of health care has been the absence of a clear, functional link between health care performance and the careers and prospects of practitioners.

Who is responsible for the incentives and disincentives that exist and for the task of reforming them? Not having the time for a detailed answer, I can say only that the nature of the incentive or disincentive locates it where it primarily belongs: in the nature of our laws, in our social and political institutions, in the several levels of our government, in the organizations that underwrite care, in consumer organizations, and so on. But $\mathbf{I}$ believe that the primary locus of leadership and responsibility belongs in the organized health care professions. It is they who should understand best what is most conducive to the most effective, efficient, and acceptable practitioner-patient interaction-if they could only raise their sights and regain their unique position as the primary advocates for the welfare and interests of their patients, individually and collectively; if they could only recapture the conviction that stewardship of quality in health care is their most urgent, most sacred obligation; if they could only see that the quality of health care is the moral foundation on which the professions must stand, and without which they will inevitably perish.

We begin to see two lines of progress toward equity in health care. Individual practitioners and provider 
institutions are responsible for treating all patients with similar needs in similar ways, rejecting all invidious distinctions. The larger issues of equity, governed by who has access to care, under what circumstances, to what extent, and of what quality, are determined by the complex processes that eventuate in public policy in our democracy. They are the responsibility, in various ways and to various degrees, of all those who participate in these processes.

But leadership does not mean ownership. Quality in health care is too precious a commodity to be entrusted to any one agency, no matter how elevated. It belongs to us all, and we each have our legitimate, necessary role to play in protecting and enhancing it.

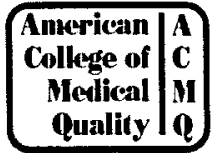

Júne 9-12

December 3-4
October 22-23 Lecture Series, Denver, CO

\section{ACMQ EDUCATIONAL CALENDAR}

Annual Conference, Hyatt Regency, Bethesda, MD

"Ensuring the Practice of Quality Medical Care in the Era of Health Care Reform"

20 Category $1 \mathrm{CME}$ credits, 20 contact hours approved by ASNA

September 10-11 Lecture Series, Los Angeles, CA

"Risk Management/Utilization Management"

"The Art \& Science of Continuous Quality Improvement" 12 Category 1 CME credits per course, 12 contact hours, approved by ASNA

Details as above

Lecture Series, New Orleans Hilton Riverside, New Orleans, LA

Details as above

To be held in conjunction with AMA House of Delegates meeting December 5-8

For further information, please call the ACMQ, tel: (301) 365-3570. 